\title{
Communicating through Architecture and the Virtual Reality. The Cultural City of the Future
}

\author{
Rudi Papa \\ "Sapienza" Università di Roma, Department of Political Science \\ rudi.papa@uniroma1.it \\ Llazar Kumaraku \\ "Sapienza" Università di Roma, Department of Architecture and Design \\ llazar.kumaraku@uniroma1.it
}

Doi:10.5901/ajis.2014.v3n4p291

\section{Abstract}

The analysis of a cultural city and the communication that it generates. The multifunctional nature of the architectonic communication seen in a material dimension and the immaterial part of it. Integrating the virtual reality technologies at the cultural heritage and inventing a new way and take advantage of the cultural content.

Keywords:smart cultural city ; communication; architecture ;virtual reality ;cultural heritage.

\section{Introduction}

The city was always been the central concept of theoretical speculation, at first on the part of philosophers, poets and at last of architects and engineers. The first ones who have talked about the "city" were: Plato in "The Republic", Thomas More in "Utopia", Tommaso Campanella in "The City of the Sun", Charles Fourier in "The Falanstère" and many other intellectuals. These books, above mentioned, describe the city in its utopic dimension, that is a place without social class injustices, an event that nowadays has no chance of occurring. In these examples the city is represented only like a community that neglects the environment. The city doesn't consist only of the community but it has also another aspect, more important than the first that is the material dimension: buildings, streets, crossroads, etc. From the mid-nineteenth century many architects and engineers work on this material aspect: Ebenezer Howard with "Garden City", Tony Garnier with "An Industrial City", Hilberseimer with "Vertical City" and many other proposals of the pioneer of modern architecture: Le Corbusier with "The Contemporary City". All these proposals have something in common: an idea of city saw as closed social and physical environment, a city that is an unicum.

Nowadays the situation is really different. The city has no limits and someone like Leonardo Benevolo theorises The end of the City, a city with a limited and closed structure opposed to the surrounding nature. Today the meta-city presents a "subjectivation" of the society, with an open and fluent nature wedded to the territorial dimension. This event happens when there is the "death" of the Modernism and the "birth" of the Postmodernism. In effect the urban and suburban sprawl exactly occurs in the Postmodernism. The community idea vanishes with the dissolution of utopias. There's no more ideologies able to join people together. The third millennium city got from the past the attention on the society and on the lived environment, our century introduces a new concept: "sustainability" usually referred to as limiting ecologic effects on the nature. The city has to be functional: it must offer a safe repair and all the necessary means to execute many human activities: drinking water, clean air, food and healthy living spaces. It has to be realized not considering cars ( as in the twentieth century) but human beings. 


\section{A Smart Cultural City. S-Art}

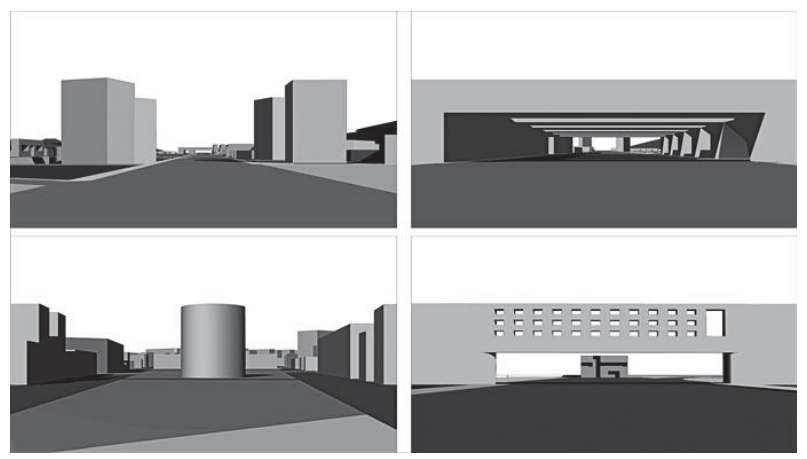

\section{S- City, Render}

Mumford $L$. : "The city is the point of maximum concentration for the power and the culture of a community».

The S'Art is a virtual proposal that has no real contest but it is an ideal city born to fill social, cultural and communicative needs of the third millennium. Its position fosters the renewable energies exploitation: solar and wind power. There's a direct exploitation of solar power by a photovoltaic systems, as solar panels and roof tiles, but there's also an indirect exploitation by a correct position of these industrial products. The environmental sustainability concept implies the respect for the nature and the human basic needs fulfilment. The communication is another aspect of the contemporary city. Our society is considered "communicative society" because today communication is everything. The word "communication" is derived from the Latin verb "communicare" which means "to share something". Now it has many other means, in general it indicates diffusion, involvement and trade of something that is not only information or knowledge but also asset or space.

The city is communicative because it tries to share areas, notions, habits and it has also to guarantee safety, wellbeing and entertainment. Venice Architecture Biennale 2012 had as keyword: "common ground" that is "sharing an area". The city emphasizes the environmental, aesthetic, social and communicative aspects. According to Umberto Eco: "Architectural language is an authentic linguistic system obeying the same rules that govern the articulation of natural languages." Its meaning grounds on the understanding and on the interpretation of the architectural space. The Architecture also means images production: these images are parts of the space and they interact with it, before reader's eyes, mixing up themselves becoming a real language communication. These aspects are the basis of the S'Art idea: in effect it is a pole interested in art structures, in cultural and intellectual work; it is a polifunctional centre of mass communication.

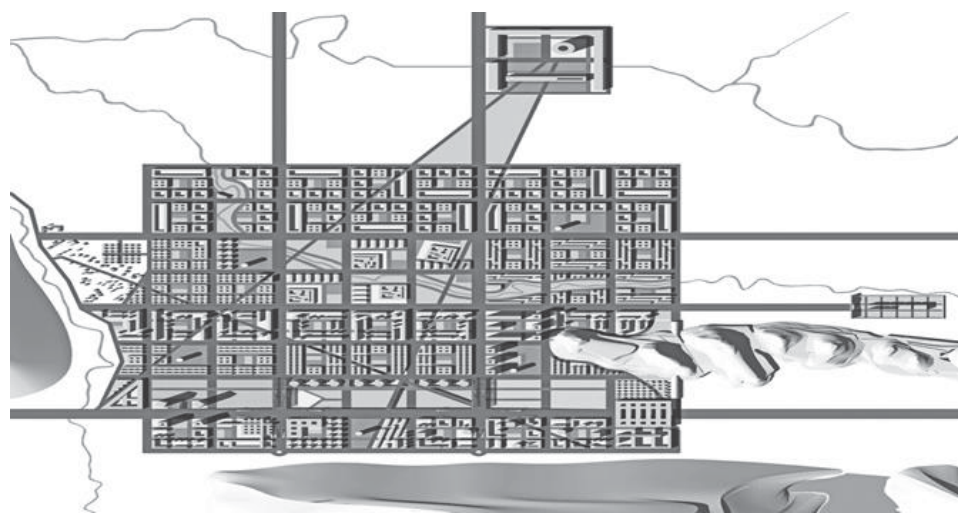

\section{S- City}

The S'Art contributes to produce and to promote culture. Concentrating an artistic production into an unique pole implies 
collaboration and a further artistic and cultural specialization. The idea of building a city for art and culture is a real cultural and communicative pole lack. Art and culture communication by the city and its architecture means to give a new dimension to the culture. There are many structures and many centres for cultural research but they are scattered on the territory. The concentration of these structures and research centres leads up to their mixture, that is positive for a cultural productivity homogeneously placed. Art improves the quality of life. The city planning and building is necessary to ride out the current crisis of thought and knowledge.

\section{S- City, Perspective 1}
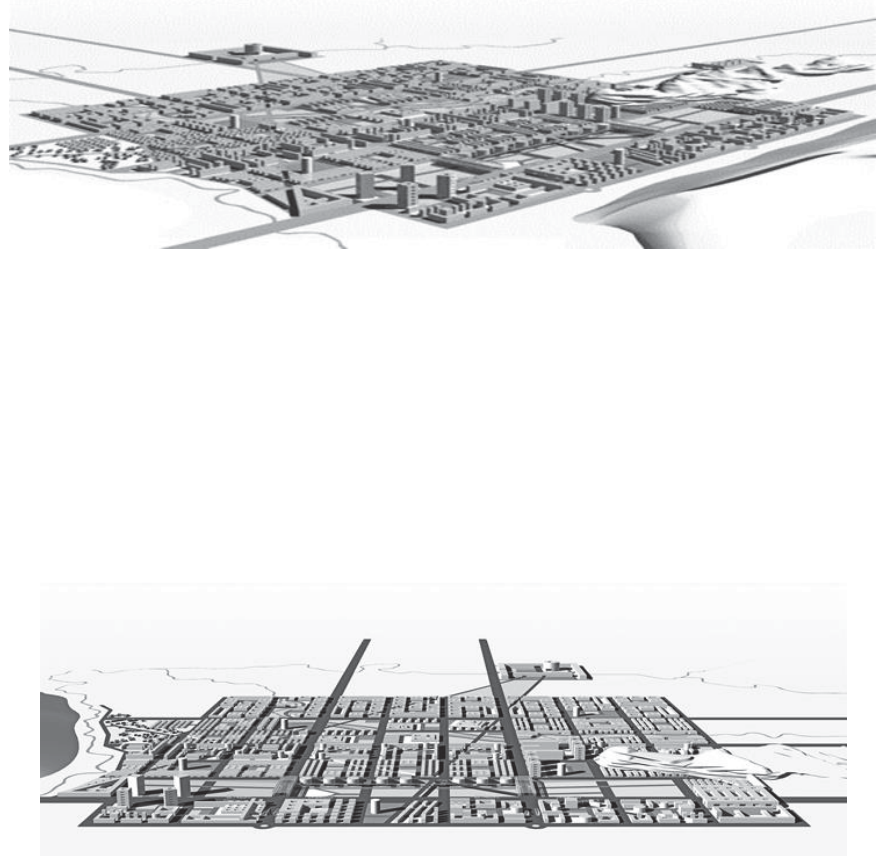

\section{S- City, Perspective 2}

\section{New Technologies in the Culture . Google Art Project Example}

New technologies and virtual reality advancement create exhibits and reconstructions, thanks to the multidimensional plan: multisensorial platforms that produce a new way of real time communication and participation. The use of information technologies applied to promotion and culture sharing, leads up to revaluate everything was impossible to do till now. Google Art Project is an example of success for these groundbreaking technologies. 


\section{Google Art Project Img}

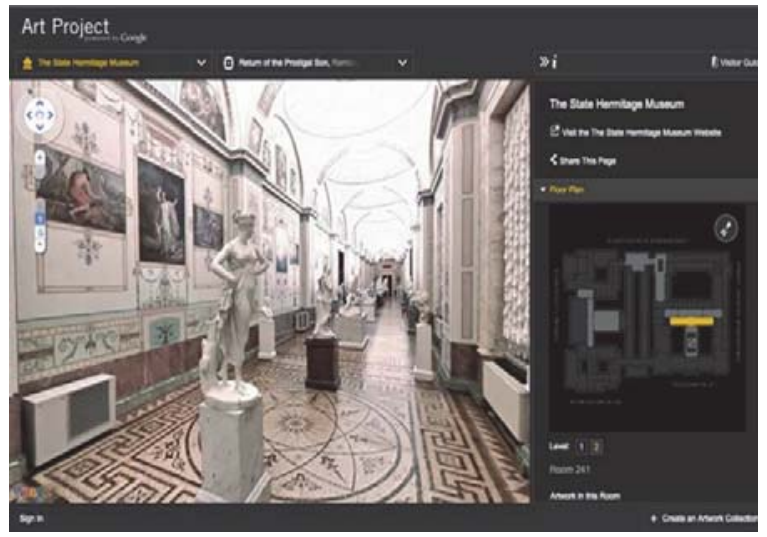

In the Google Art Project Google society makes its technology available to the art:11 cities, 9 countries, 17 museums, 17 gig pixel images, 1061 high resolution images of artworks, 385 galleries, 486 artists, 6000 virtual tours. The virtual tour enables users to access high-resolution images. The project was launched on 1 February 2011 by Google, in cooperating with the Tate Gallery, London; the Metropolitan Museum of Art, New York City; the Uffizi, Florence; the Capitoline Museums, Rome.On April 2012 a major expansion to the Art Project as it signed partnership agreements with 151 museums from 40 countries.

This platform now features more than 32,000 artworks from 46 museums, and the image acquisition process is underway at the remaining partner museums. The project includes as well works from institutions like the Art Gallery of Ontario, the White House, the Australian Rock Art Gallery at Griffith University, the Museum of Islamic Art, Doha, and the Hong Kong Museum of Art. Additionally, Google launched a second, improved version of the website with new features, enhanced search capabilities, and a series of educational tools. The update to at second-generation platform should be a global resource, accordingly, the Art Project is now available in 18 languages, including Bahasa, English, French, Japanese, Polish, and Portuguese.

This is a new experience available to everyone. Everybody can easily admire many artworks without being on site. The view on monitor screen and life view are not the same thing, but Google Art Project can give an high- resolution view of artworks, seeing many details generally out of reach.

\section{Conclusions}

We have analysed how the architecture is available to communicate something and its main function is to give more information about the history, like so a presentation. The virtual reality and the new technologies, joined to the modern architecture, offer a chance to promote and to share that culture, which was only an intellectual domain till now. A technological city allows to communicate something and to appreciate the past through the present. Technological progress offers conditions and means to realize all that was impossible to do until this time. The new digital society will be more and more interactive and the knowledge sharing will guarantee a more natural progress in the future.

\section{References}

Benevolo L., La fine della città, Laterza, Bari 2011.

Eco, U. Function and sign: The Semiotics of Architecture, in Sign. 1980

Google Art Project. http://www.googleartproject.com/fags

Folgieri, R., VR for Cultural Heritage Valorization: A. Communication Problem", 2011.

Mumford L., The Culture of Cities, Hartcourt Brace \& Company, San Diego 1938 Edizioni di Comunità, Milano 1953.)

Marinetti, F.T. The Futurist Manifesto (1909).

Richard L. Meier .A communications theory of urban growth. M.I.T. Press, 1962

Turner, F. (2005). Where the counterculture met the new economy: The WELL and the origins of virtual community. Technology and Culture,

Wileman, R. E. Visual communicating. Englewood Cliffs, NJ: Educational Technology Publications (1993) 